\title{
TURISMO COMUNITARIO PRO POBRE Y SU DEFINICIÓN DE POBREZA
}

\author{
Martha Marivel Mendoza Ontiveros \\ marivelmo@hotmail.com \\ Rafael Hernández Espinosa \\ ra_fa@hotmail.com \\ Universidad Autónoma del Estado de México
}

El escrito parte de revisar el enfoque del turismo comunitario como mecanismo para combatir la pobreza de familias indígenas y campesinas. Se discute la definición del concepto de pobreza que sustenta al turismo pro pobre, el cual, entre otras cosas, supone una visión del mundo cuantitativa y universalmente válida, una perspectiva etic, sin contemplar que la pobreza es una construcción social que implica también aspectos cualitativos, como los elementos ideológicos inherentes a su definición o las significaciones que subyacen en el punto de vista de los sujetos considerados pobres -perspectiva emic-. La noción predominante sobre la pobreza ha dejado de lado la multidimensionalidad del fenómeno y la necesidad de estudiar las dinámicas que reproducen la desigualdad y conducen a la exclusión social, lo cual no permite comprender por qué el turismo comunitario pro pobre, incumple con el propósito de mitigar la pobreza.
\end{abstract}

Palabras clave: Turismo rural comunitario, pobreza, exclusión social, construcción social.

\section{PRO-POOR COMMUNITY TOURISM AND ITS POVERTY DEFINITION}

The paper begins by revising the point of view of community-based tourism as a mechanism to combat poverty among indigenous and peasant families. It continues by discussing the definition of poverty sustained by pro-poor tourism, which, among other things, presupposes a quantitatively and universally valid vision of the world, an etic perspective. Furthermore, said definition does not consider that poverty is a social construction that also involves qualitative aspects, such as the ideological elements inherent in its definition or the meanings underlying the point of view of people considered poor -an emic perspective. The predominant notion of poverty has left aside the multidimensional nature of this phenomena, as well as the need to study the dynamics that reproduce inequality and contribute to social exclusion, which does not allow us to understand why pro-poor community tourism fails to alleviate poverty.

Key words: Community-based rural tourism, poverty, social exclusion, social construction. 
$\mathrm{D}$ esde sus inicios, los estudios antropológicos del turismo han estado vinculados con el desarrollo. En varios contextos se ha preguntado: el turismo, ¿es un pasaporte para el desarrollo? (De Kadt, 1979); si es así, ¿bajo qué circunstancias? y ¿en qué condiciones? (Cañada y Gascón, 2007). Actualmente, el turismo como vía de desarrollo representa un tópico clásico en los estudios de los antropólogos. Por ello, el fenómeno turístico y su promoción no pueden comprenderse fuera del paradigma desarrollista en el que se inscriben, sobre todo desde la segunda mitad del siglo pasado, por haber logrado una posición central en las políticas de alcance global (Milano, 2016).

Gascón (2011) señala que, tras la crisis de la década de 1980 y con la generalización de las políticas económicas neoliberales en los noventa, la aportación de Latinoamérica a la economía mundial fue constreñida a centrarse en la producción de alimentos y materias primas para la exportación, recuperando la tesis principal del modelo librecambista y primario-exportador decimonónico (Gascón, 2010). Pero también se estimularon otras opciones complementarias, como la maquila o el turismo.

Dentro de las diversas prácticas turísticas, el turismo comunitario, por sus especiales características, ha sido planteado como una estrategia para el desarrollo local y, a partir de la puesta en marcha de las metodologías Pro-Poor Tourism (PPT) y Turismo Sostenible-Eliminación de la Pobreza (Sustainable Tourism for Eliminating Poverty, ST-EP), ha entrado con fuerza en la agenda política de la cooperación internacional. De esta manera, el turismo rural comunitario surge por la necesidad de generar alternativas económicas que diversifiquen los ingresos de las familias del campo, enfrentadas a un modelo de desarrollo rural depredador de los recursos naturales, que ha profundizado la inequidad y concentrado la propiedad de la tierra, generando desempleo, emigración y deteriorando el vínculo de la comunidad rural.

No obstante, los propios impulsores del PPT no han podido dar ejemplos que demuestren los beneficios reales para los pobres cuando estos se dedican al turismo (Ashley y Goodwin, 2007). Las voces críticas del PPT afirman que solo se ha enfocado en el nivel micro, como un producto nicho en los casos de ecoturismo y turismo rural. Asimismo, se ha puesto poca atención en los vínculos con el mercado. Los recursos económicos de organismos nacionales e internacionales se destinan a proporcionar capacitación, en el mejor de los casos, o a la construcción de infraestructura, en su mayoría, pero los productos fracasan por no tener una demanda doméstica o internacional, y esto redunda en que no se mejoren los medios de vida. La mayoría de las veces, se anima a las comunidades a iniciar proyectos turísticos y, luego de invertir dinero, trabajo y propiedades, los turistas no llegan (Ashley y Goodwin, 2007).

Aquí se discute la definición de pobreza que subyace en la propuesta del turismo en el combate de esta, y se pretende complementar su abordaje para comprender las causas de su fracaso o su éxito incorporando al análisis a los teóricos de la exclusión. La investigación convencional de la pobreza ha dejado fuera la importancia de las relaciones sociales, la multidimensionalidad del fenómeno y la urgencia de estudiar las dinámicas que conducen a la exclusión social. 
El escrito inicia examinando el turismo rural comunitario como mecanismo para combatir la pobreza de familias indígenas y campesinas. Después se analiza el concepto de pobreza, que sustenta al PPT, y que es una definición tecnocrática fundamentada en la teoría económica; se debate el concepto caracterizándolo desde la imposición de una visión del mundo que se erige como el modo universalmente válido, una perspectiva etic, sin tener en cuenta que la pobreza es una construcción social que implica aspectos ideológicos, además de no considerar el punto de vista de las personas identificadas como pobres, es decir, la perspectiva emic. Por último, una forma de avanzar en el análisis es plantear el fenómeno de la pobreza vinculado a la exclusión social, para comprender por qué el turismo comunitario pro pobre incumple con el propósito de mitigarla.

\section{Turismo comunitario pro pobre}

En las décadas recientes, incluso antes del neoliberalismo, el turismo se impulsó y se propuso como una estrategia fácil y rápida de desarrollo y de lucha contra la pobreza, capaz de generar elevados beneficios con muy poca inversión, pues sus principales elementos de atracción (el paisaje y la cultura autóctona) ya estaban gratuitamente establecidas (Gascón, 2011).

El binomio turismo-desarrollo llevó a promover un turismo gestionado por unidades familiares campesinas o indígenas, por comunidades, por empresas comunitarias o por cooperativas, con la finalidad de contraponerse a los modelos de turismo dominantes, como el de enclave, que han mostrado muy pocos beneficios para el mundo rural. El turismo así gestionado, que en las últimas décadas se ha denominado turismo rural comunitario, debía ayudar a la mejora de las pauperizadas economías campesinas, ofreciendo un aporte de recursos económicos y diversificando sus fuentes de ingresos.

Sin embargo, el turismo rural comunitario, a pesar de ser novedoso y reciente, se comenzó a gestar en 1967, fecha en que la Organización de las Naciones Unidas declaró el Año Internacional del Turismo, y algunas de sus agencias empezaron a financiar estudios de mercado, planes maestros, capacitación y restauración de áreas culturales (cuadro 1).

En la primera década del siglo XXI, las bases conceptuales de estas estrategias comenzaron a plasmarse en los proyectos turísticos de las agencias de desarrollo internacionales, bajo diferentes formas: turismo comunitario, turismo rural comunitario, turismo de base local, turismo solidario, turismo voluntario, etc. La cooperación internacional para el desarrollo ha sido aceptada como principio básico y se ha liberalizado el sector turístico, concibiéndolo como panacea para todos los males.

Durante la Cumbre Mundial sobre el Desarrollo Sostenible, celebrada en septiembre de 2002 en Johannesburgo (Sudáfrica), se presentó el Programa Turismo Sostenible-Eliminación de la Pobreza (ST-EP) para contribuir a dos objetivos del milenio: el combate a la pobreza extrema y la promoción de la igualdad de género: 
Cuadro 1. Cronología del turismo comunitario pro pobre

\begin{tabular}{|c|c|}
\hline Décadas & Caracterísitca \\
\hline 1970 & $\begin{array}{l}\text { Entre } 1969 \text { y } 1977 \text { se financiaron alrededor de } 24 \text { proyectos en } 18 \text { países (Pleumaron, } \\
\text { 1994; Unesco, 1976). }\end{array}$ \\
\hline 1980 & $\begin{array}{l}\text { Los impactos del turismo no pasaron desapercibidos, e incluso dieron lugar a un } \\
\text { movimiento apoyado por el Consejo Mundial de Iglesias, que introdujo la crítica al } \\
\text { desarrollo turístico en la agenda social: la Ecumenical Coalition on Third World Tourism } \\
\text { (ECTWT). }\end{array}$ \\
\hline \multirow[t]{4}{*}{1990} & $\begin{array}{l}\text { Hubo esporádicas referencias a la relación entre turismo y desarrollo sostenible desde } \\
\text { instancias políticas y del sector de organizaciones no gubernamentales (oNG). }\end{array}$ \\
\hline & $\begin{array}{l}\text { Empero, en Europa, la plataforma Tourism European Network (TEN), en colaboración con } \\
\text { la Coalición Ecuménica de Turismo (ECOT, anteriormente ECTWT), y con financiamiento de } \\
\text { ONG alemanas, siguieron alimentando esta visión crítica. }\end{array}$ \\
\hline & $\begin{array}{l}\text { Fue a partir de mediados de la década de los noventa que algunas oNG empezaron a } \\
\text { considerar el turismo como una estrategia adecuada para recaudar fondos, tanto para } \\
\text { su propia financiación (turistas que visitan los proyectos de cooperación) como para } \\
\text { beneficiar a las comunidades anfitrionas con las que trabajaban. }\end{array}$ \\
\hline & $\begin{array}{l}\text { En esta década, oNG de países de acogida o beneficiarios comenzaron a poner en marcha } \\
\text { proyectos turísticos financiados por entidades y organizaciones occidentales. }\end{array}$ \\
\hline \multirow[t]{6}{*}{2000} & $\begin{array}{l}\text { En 1999, tras las primeras iniciativas de la Unesco y del BM, surgió la metodología Pro } \\
\text { Poor Tourism con su visión: Putting poverty at the heart of the tourism agenda, la cual } \\
\text { enfocó el interés de las agencias internacionales de desarrollo hacia el sector turístico. }\end{array}$ \\
\hline & $\begin{array}{l}\text { Los tres creadores y principales teóricos involucrados con la implementación del PPT son } \\
\text { Caroline Ashley, Harold Goodwin y Dilys Roe. }\end{array}$ \\
\hline & $\begin{array}{l}\text { Desde el inicio del PPT, la Organización Mundial del Turismo (омT) ha publicado gran } \\
\text { cantidad de manuales teóricos y prácticos que adoptan las bases teóricas del PPT y, en } \\
\text { 2002, lanzó la iniciativa Sustainable Tourism for Eliminating Poverty. }\end{array}$ \\
\hline & $\begin{array}{l}\text { El primer manual Turismo y atenuación de la pobreza, publicado en } 2002 \text {, brindaba } \\
\text { un análisis de la interrelación entre el turismo y el desarrollo económico, incluyendo } \\
\text { factores tales como la mejora de los beneficios económicos, la mejora del acceso } \\
\text { para las pequeñas y medianas empresas y la intensificación de los efectos locales del } \\
\text { turismo para los pobres. }\end{array}$ \\
\hline & $\begin{array}{l}\text { Una segunda publicación de la omT, de } 2004 \text {, Turismo y atenuación de la pobreza: } \\
\text { recomendaciones para la acción, proponía un marco de siete medidas prácticas para la } \\
\text { aportación eficaz de beneficios económicos y sociales para los pobres. }\end{array}$ \\
\hline & En 2005, se creó la Fundación ST-EP con sede en Seúl, en la República de Corea. \\
\hline
\end{tabular}

Fuente: Milano (2016). 
En este documento se argumentaba, si bien el turismo se comercializa internacionalmente, se consume en el punto de producción. En otras palabras: los turistas visitan la fábrica. Es a nivel del destino que deben maximizarse las oportunidades para que los residentes obtengan beneficios de esta industria de exportación si el turismo se quiere utilizar para reducir la pobreza. Central en el debate sobre turismo y desarrollo son los temas de la forma de empleo y otros beneficios económicos que pueden ser maximizados a nivel local en los destinos, y cómo se pueden minimizar los impactos sociales y ambientales negativos. Los principios y los enfoques que maximizan los impactos económicos del turismo a escala local son los que están asociados con el enfoque del Pro-Poor Tourism, el cual se define por tener un enfoque basado en los beneficiarios [Goodwin, 2013, p. 388].

El PPT considera que, al incrementar los ingresos de la población más depauperada, el turismo es una eficiente herramienta para reducir la pobreza en los países menos desarrollados (Gascón, 2011). Para tal propósito se plantean tres ámbitos de actuación:

1. Aumento de oportunidades de trabajo asalariado.

2. La creación de microempresas locales.

3. La generación de ingresos comunitarios.

Para lograr esos objetivos se propone una intervención financiando proyectos de turismo rural comunitario y el apoyo de políticas empresariales turísticas de gran capital que generen empleo directo e indirecto para la población local. Tal mecanismo de cooperación internacional busca incidir en la realidad para transformarla, y se basa en el paradigma de que la pobreza puede combatirse incrementando los ingresos de los pobres hasta alcanzar un mínimo de bienestar (Gascón, 2011).

Al referirnos a casos específicos de resultados empíricos positivos la evidencia es limitada, porque no se ha realizado un monitoreo sistemático y documentado sobre los cambios en los medios de vida de la gente pobre debido al turismo. No se sabe de ningún destino donde la gama completa de impactos del desarrollo del turismo en todos los niveles de pobreza (no solo de un grupo) haya sido rigurosamente evaluada. Hacen falta estudios longitudinales que comparen con precisión y minuciosidad antes del turismo y después del turismo, existe poca literatura que cuantifique resultados tangibles, y lo que se presenta como casos de éxito genera más preguntas que respuestas. Sin embargo, algunos autores piensan que se puede hablar de casos que ponen de relieve los beneficios de este tipo de proyectos.

En Experiencias de turismo comunitario en Nicaragua. Aportes a la economía campesina, Cañada y Fandiño (2009) exponen cuatro casos, a decir de ellos, de procesos exitosos de introducción del turismo, que se han dado en cooperativas cafetaleras en Centroamérica, las cuales, gracias a la introducción del turismo, han logrado ampliar sus fuentes de ingresos e incidido en los procesos de desarrollo rural. En términos generales argumentan que los principales aportes del turismo comunitario en estos ejemplos son una mayor demanda de alimentos, por lo que algunas familias han reducido la extensión de tierra dedicada a un solo cultivo destinado al mercado, en este caso café, y han preferido diversificar y aumentar la producción de verduras y hortalizas para consumo directo. Señalan que 
los nuevos empleos vinculados al turismo no solo han generado ingresos monetarios, permitiendo que las familias involucradas en estas actividades mejoren su bienestar y condiciones de vida, sino que también han contribuido a una mejora de la alimentación familiar y a la educación de hijas e hijos. Además, con la ampliación de las actividades productivas que las familias campesinas pueden llevar a cabo en sus territorios, en particular por parte de mujeres y jóvenes, se ha ampliado la base social que se beneficia directamente de las actividades vinculadas al campo.

Por otro lado, a partir de sistematizar nueve experiencias de turismo rural comunitario en Nicaragua y Guatemala, Pérez, Barrera Pérez, Peláez y Lorío (2010) sostienen haber identificado procesos positivos como el incremento en el ingreso de los hogares, mejora en el consumo, principalmente en ropa y en inversiones sociales relacionadas con infraestructura básica: escuelas, caminos y puestos de salud. Precisan además que los ingresos complementarios del turismo rural comunitario aumentan el gasto familiar, la compra de insumos agrícolas y de ropa, con lo cual han expandido las áreas de siembra y, en consecuencia, los niveles de seguridad alimentaria; de igual manera, hay mejoras en las viviendas de quienes participan en el servicio.

Pérez et al. (2010) afirman que, en cuanto a la generación de empleo, por lo general, el turismo representa para la población local un empleo estacional, poco calificado y suele ser inestable. Asimismo, prestar servicios a los visitantes ha sido todo un reto para ellos, iniciando con el cambio cultural de cobrar por "el servicio", pasando por aprender español y, con limitados recursos, levantar la infraestructura de alojamiento y de comedores. Esta inversión ha sido bastante intensiva en mano de obra, por lo que el aporte de los comunitarios ha sido relevante, al sustituir actividades propias para garantizar su existencia por una actividad de futuro.

No obstante, a la luz de los argumentos a favor, existe una cantidad de opiniones críticas acerca del papel del turismo como una vía para aliviar la pobreza.

\section{Las críticas al turismo pro pobre}

Las acciones del turismo pro pobre están dirigidas a favorecer al sector empresarial, confiando en que una parte de los beneficios escurrirán hacia abajo, es decir, hacia la población menos favorecida, al activarse el denominado efecto trickle down, "goteo" o "derrame". Sin embargo, estas estrategias no han estado exentas de críticas. Por ejemplo, el PPT no solo no pone en duda el modelo económico dominante, sino que busca como socio al capital turístico transnacional, de forma que quienes más se han beneficiado han sido los inversionistas de capital foráneo y las agencias internacionales de desarrollo. Así, es altamente cuestionable el resultado de la redistribución de los ingresos.

Según sus críticos, el problema fundamental de esta estrategia es que no tiene en cuenta la desigualdad existente entre los distintos actores relacionados con la actividad turística y cómo el mayor desarrollo de las grandes estructuras empresariales genera subordinación, 
dependencia y vulnerabilidad de los otros actores, acentuando las diferencias sociales preexistentes (Cañada, 2011).

De hecho, lo observado es que las grandes empresas turísticas están tratando de captar parte de los fondos de la cooperación internacional, en un modelo en el que gana terreno el sector empresarial desplazando en el interés a algunos grandes donantes, a las ONG O a los mismos Estados. Esta perspectiva estima que la cooperación debe facilitar e impulsar las dinámicas de internacionalización de la empresa turística y buscar formas de vinculación e inclusión de los "pobres" en estas estructuras empresariales exitosas en el mercado global (Cañada, 2015). Empero, consolidar este tipo de estrategia productiva no es tarea fácil. Más allá de los muchos proyectos de cooperación que orientan a las comunidades hacia una "nueva ruralidad", mantener en el tiempo este tipo de apuesta requiere mucho esfuerzo, voluntad y preparación por parte de las familias campesinas, comunidades rurales o pueblos indígenas implicados.

Bajo este esquema de turismo, las comunidades sufren un proceso de intervención para "ser convertidas" en espacios con "calidad turística", bajo el entendido de responder a la demanda conforme a estándares de calidad sugeridos por los grupos promotores y operadores del turismo internacional. Los espacios rurales con alta pobreza participan del turismo con claras desventajas, dada la dificultad de invertir recursos financieros en el desarrollo de una oferta de servicios competitiva desde el punto de vista del mercado turístico, además de las limitaciones sociales, infraestructura pública disponible y adecuada, tal como se encuentran en los espacios rurales de rezago social en países pobres (Picón Cruz y Hernández Ulate, s. f.).

Asimismo, el turismo comunitario ha sido fuertemente cuestionado como modelo de desarrollo debido a su bajo impacto en materia de empleo e ingresos, a la excesiva dependencia de financiamiento y asesoría externa, a la monopolización de beneficios por parte de las élites locales, desigualdades dentro de las comunidades o falta de capacidad para hacer funcionar los negocios de forma operativa (Gascón, 2013).

Se ha planteado también que, a causa de la desigual situación en la que se hallan las poblaciones más empobrecidas con respecto a los grandes capitales turísticos, este tipo de intervención amplía la brecha en cuanto a la capacidad política de las comunidades rurales para tomar decisiones sobre los aspectos que afectan a esos territorios y sus recursos, lo cual contribuye a incrementar su pobreza relativa. Por más que algunas políticas de cooperación puedan apoyar iniciativas comunitarias, su lógica pasa por una relación de los sectores sociales más desfavorecidos en términos de supeditación y subordinación hacia la gran empresa (Pinto Faria e Hidalgo Moratal, 2012; Gascón, 2012; Gascón, 2013).

Por su parte, Jiménez López y Cavazos Arroyo (2012, p. 453) afirman que el turismo orientado a los pobres (TOP) no se sustenta en un modelo o teoría determinada ni busca instaurar un cambio estructural, sino que se trata de una orientación o aproximación pragmática que pretende disminuir la pobreza en zonas que pueden ofrecer algún tipo de turismo, en donde los beneficios retornen a los más desfavorecidos. 
Forstner (2004) postula que las iniciativas de turismo rural comunitario pueden maximizar las ganancias del sector servicio para las comunidades rurales. Pese a ello, precisa que su principal cuello de botella está asociado al proceso de intermediación del servicio, pues tienen limitado acceso a mercados, por tanto, las ganancias de las comunidades estarán asociadas al poder de negociación que tengan con un operador turístico. Cañada y Fandiño (2009) advierten la obligación de ser conscientes de las posibilidades reales del mercado turístico y evitar falsas expectativas. Lo anterior hace necesario reconocer que no todas las comunidades en el ámbito rural pueden esperar el mismo éxito con el turismo, sencillamente porque no es posible que la demanda pueda ampliarse de forma indefinida. Poner en marcha iniciativas turísticas comunitarias es complicado y requiere voluntad, esfuerzo, organización, pero también algunas condiciones (atractivos turísticos, accesibilidad, diferenciación, etcétera).

Mitchell y Muckosy (2008) señalan que el turismo rural comunitario presenta dos problemas: débil (pobre) gobernanza y débil (pobre) acceso a mercados. Forstner (2004) identifica solo la segunda, y propone como solución el aprovechamiento del capital social para superarla, es decir, que no son pobres en cuanto a gobernanza de redes, aunque se considera que el comité comunal y la gerencia del servicio deben ser estructuras ligadas, pero con límites bien definidos.

Más de un autor advierte que el turismo rural comunitario debe ser parte de una estrategia de desarrollo turístico alternativo al modelo dominante. Pero únicamente puede ser una parte, Por sí solo no puede ser la alternativa. Necesita construir una alianza con la pequeña y mediana empresa turística local y nacional. El turismo, en definitiva, puede ser una forma de diversificar las actividades económicas de una comunidad, pero no la única ni necesariamente la primordial, y mucho menos una opción para todo el mundo. El fortalecimiento de la economía de base comunitaria, sea a través de la agricultura, la ganadería, la pesca, la agroindustria, la apicultura o el turismo, de forma diversificada y complementaria, en la que el protagonismo y control de los recursos esenciales queda en manos de la gente organizada del lugar, es la clave que puede permitir a las comunidades seguir viviendo en sus territorios tradicionales (Cañada y Fandiño, 2009).

Por último, un elemento que ha desatado críticas trascendentales al turismo comunitario pro pobre es la definición de pobreza que subyace en él, donde la pobreza se concibe como la privación de las necesidades vinculadas al mínimo vital y los indicadores son el ingreso per cápita o el valor de una canasta de consumo (Pinto Faria e Hidalgo Moratal, 2012). Según Gascón (2011, p. 4), a partir de esta definición de pobreza, la finalidad del PPT es "el incremento de los ingresos de los sectores más desfavorecidos de la población, aunque estas ganancias sean marginales y otros acaparen la mayor parte de los beneficios que genera la actividad". Tal concepción se sustenta en que, a pesar de que los beneficios para la población local no sean de gran relevancia a nivel macro, pueden significar un aporte esencial para las grandes masas sumergidas en la pobreza. No importa si afecta a la pobreza absoluta o la pobreza relativa. 
Ello fortalece la interpretación de que la pobreza, al igual que el bienestar y el progreso, son construcciones sociales. De otro modo no podría calificarse como exitoso el caso en el que la empresa comunitaria reciba cuatro veces al año a un grupo de estudiantes y que con ello mejoren sus ingresos de acuerdo con los entrevistados. Asimismo, en los análisis se ponen en evidencia las ventajas que tienen los directamente relacionados con el turismo y no la situación de los que, siendo parte de la comunidad, quedan excluidos de las ganancias. Este esquema es semejante a los destinos de turismo tradicional en donde se valoran como exitosos a partir de las ganancias que obtienen los grandes empresarios y no de la situación económica de la población trabajadora.

De cualquier modo, es necesario hacer una reflexión más puntual sobre las definiciones de pobreza que subyacen en los programas de desarrollo donde se ubica el PPT, así como definiciones alternativas y las repercusiones que podrían tener no solo en la gestión del turismo, sino en ámbitos más generales de la sociedad.

\section{La pobreza como construcción social}

La pobreza, en su carácter de fenómeno social, ha sido abordada desde varias disciplinas, principalmente la economía y la sociología. Sin embargo, la antropología también ha hecho presencia en la discusión del concepto aportando reflexiones interesantes. En este sentido, resulta pertinente analizar el concepto distinguiendo dos aspectos en las distintas perspectivas académicas de su estudio y su medición, uno objetivista, que podríamos adscribir a una perspectiva etic, de carácter más cuantitativo, y otro más cualitativo y subjetivista, que podríamos adscribir a una perspectiva emic.

El enfoque etic involucra el estudio de las dimensiones que inciden en las condiciones materiales que permiten definir los umbrales de la pobreza. En esta discusión destacan diferentes definiciones y modelos para su medición, desde el de necesidades básicas insatisfechas (NBI), pasando por el de la línea de pobreza (LP), hasta el método de medición integrada de la pobreza (MmiP) (Cuéllar, 1995; Hernández, 2001). Tales modelos están dirigidos sobre todo a identificar los umbrales cuantitativos para decidir a quién puede considerarse pobre y a quién no (Boltvinik, 2001). Para ello se tienen en cuenta la insatisfacción de necesidades básicas o los niveles de ingresos. La pobreza se interpreta, desde un punto de vista monetario, como la insuficiencia de recursos para adquirir la canasta de consumo mínima aceptable socialmente (Herrera, 2002). Esta perspectiva, paradigma dominante en los estudios empíricos, estima el costo de una canasta mínima de alimentos y servicios y, por lo tanto, califica como pobres a todos aquellos cuyo consumo está por debajo de este valor. El segundo enfoque es el de la pobreza relativa, que reconoce como pobres al grupo de personas cuyos ingresos están por debajo de un determinado nivel, e insiste en la capacidad de comprar los bienes y servicios considerados básicos y no su consumo efectivo. Estos aspectos han predominado en las polémicas, es decir, si lo uno o lo otro puede determinar el umbral, o si se tienen que hacer modelos más complejos que incluyan 
también características contextuales y relativas como el periodo histórico o la riqueza de la nación en cuestión, entre otras cosas. Todo, con la finalidad de generar un consenso numérico en cuanto a la magnitud "real” de la pobreza, y así producir mejores programas para combatirla.

Es precisamente la intención de generar un conocimiento "real” u objetivo de la pobreza lo que permite entender esta perspectiva como etic, ya que se trata de identificar sus elementos objetivos independientemente de las significaciones o las experiencias subjetivas de quienes quedarían clasificados en esa condición.

La perspectiva emic, por su parte, se caracteriza por el interés de recuperar una noción de la pobreza desde el punto de vista del grupo, comunidad o actor. El término cultura de la pobreza que acuñó Oscar Lewis (1961) figura como una aproximación pionera de esta perspectiva; mas esta se ha complejizado, pues se incluyen los aspectos significativos de la experiencia de las personas, sus modos particulares de entender el mundo y sus formas de autoadscribirse en las categorías que las versiones oficiales (etic) señalan como pobreza; es decir, el cómo se producen desde ahí determinadas significaciones de la pobreza. Ello implica necesariamente privilegiar el punto de vista interno de una comunidad o grupo, frente a la posición externa, lo etic. Se parte de la visión de los sujetos, sus categorizaciones, valoraciones y percepciones en torno a la pobreza, y el papel del investigador es el de intérprete de lo interpretado por los sujetos (Ceirano, 2000).

Desde esta perspectiva puede señalarse un amplio abanico de significaciones de la pobreza, más allá de lo económico, que van desde las cualidades personales y espirituales, como la humildad y la sencillez, entre otras virtudes, hasta las que se refieren a aspectos negativos relativos a las carencias materiales y los sufrimientos derivados. No obstante, estos aspectos simbólicos y culturales de la pobreza en general son poco tratados, quizá porque a veces son los menos visibles y los que alejan más la definición de la idea más material de la pobreza (Estivill, 2003).

De tal suerte, no siempre, ni de manera irremediable, las definiciones emic y etic de la pobreza se corresponden; de hecho, por lo general se hallan en una dinámica de negociación en la que se confrontan diversos discursos sobre lo que es la pobreza y lo que no. Empero, a través de los procesos legitimadores, mediados por las instituciones, se genera un efecto decisivo en la construcción social de la realidad (Berger y Luckman, 1972). Como señala Gergen (2007), la socialización del conocimiento científico social tiene repercusiones de gran trascendencia en el comportamiento de la población al prescribir de forma indirecta la deseabilidad de las condiciones y las conductas sociales. Los organismos oficiales basados en conocimientos científicos e intelectuales tienen un efecto importante en la población a la hora de difundir sus "descubrimientos".

Con base en lo anterior, puede sostenerse que en el proceso de construcción social de la pobreza participan de manera notable los discursos científicos que determinan los criterios a partir de los cuales debe evaluarse y calificarse la incidencia "real" de la misma, así como los mecanismos considerados pertinentes y adecuados para combatir esa 
condición. Con todo, debe tenerse en cuenta que en este proceso de construcción social también existe una fuerte carga ideológica que está presente tanto en la explicación de las causas de la pobreza como en la justificación de los mecanismos de alivio.

Desde una perspectiva del conflicto social se piensa que la imposición de ideologías por parte de los sectores dominantes requiere la apropiación de los medios de producción intelectual a través de los cuales se generan nociones de la realidad acordes con sus intereses (Collins, 1994). En este sentido, puede decirse que la construcción social de la pobreza no es un campo de disputas simbólicas equitativas, pues la parte más influyente corresponde a quienes tienen la voz legitimada por las instituciones y organismos que representan los intereses de los sectores hegemónicos.

La teoría económica de la pobreza induce, por un lado, la colonización cuantitativa en su delimitación y, por el otro, impone una consideración estática de la misma, en la que se obvian las relaciones sociales y los conflictos entre los individuos (Ortiz Sandoval, 2004). Desde una postura tecnócrata neoliberal, medir es la consigna, la cuantificación deriva del credo supremo de la maximización de la ganancia y todo lo que no sea mesurable y cuantificable no tiene dignidad conceptual ni legitimidad. El punto central de ello, como apunta Ortiz Sandoval (2004), es la separación entre dos clases de sujetos, los pobres y los no pobres, que alude a la distinción de estamentos diferenciados por su posición en la estructura de consumo. Al hacer esto, se desviaría la atención de un conflicto de relaciones de poder hacia una visión meramente mercantil, donde la mediación fundamental está a cargo del Estado y la democracia capitalista. Así, el núcleo de la desigualdad social es compensado ideológicamente como igualdad abstracta en la esfera jurídico-política. Es por ello que en las sociedades democráticas las luchas y formas de protesta social en la relación capital-trabajo se juzgan poco racionales, pues de lo que se trata es de dedicar más empeño a la participación en el mercado, como productor y como consumidor, de lo cual derivarían, a la larga, necesarias recompensas (Ortiz Sandoval, 2004). Este es un aspecto central de la dimensión ideológica en el proceso de construcción social de la pobreza. No obstante, la igualdad política en la democracia no solo coexiste con la desigualdad económica, sino que la deja intacta en esencia.

Por todo esto, es posible establecer que las limitaciones actuales de los programas y las acciones institucionales para el bienestar social se derivan de la conceptualización de la pobreza subyacente en los mismos. De ahí que sea indispensable dirigir la mirada hacia otros elementos conceptuales más holistas que permitan incluir aspectos cualitativos relevantes, los cuales podrían observarse considerando la perspectiva emic y que, además, no contribuyan a la reproducción de las condiciones de injusticia y desigualdad social. Se propone que un concepto útil para tal fin es el de exclusión social, pues con el apoyo de este recurso heurístico será posible avanzar en el diseño de mecanismos más efectivos de intervención para el bienestar social, entre los que puede incluirse el turismo. 


\section{Turismo, desigualdad y exclusión social}

Un enfoque que puede fungir como puente o bisagra entre las perspectivas emic y etic de la pobreza se encuentra en los aportes de Amartya Sen (2000), quien plantea que la falta de ingresos es una de las principales causas de la pobreza, pero que el análisis no debe limitarse a este factor. Sen explica el tema de la pobreza y la desigualdad social y económica a partir del análisis de la igualdad. Si bien en todas las teorías de orden social se busca la procuración de la igualdad en algún ámbito, estas pueden resultar ineficaces y conllevar a la desigualdad en otros. Para Sen, la idea de igualdad se enfrenta con dos aspectos fundamentales. En primer lugar, la profunda diversidad humana y, en segundo, la multiplicidad de variables a partir de las cuales puede juzgarse la igualdad.

Para Sen la pobreza debe entenderse como la privación de capacidades; este enfoque se centra en las privaciones que son intrínsecamente importantes, a diferencia de los ingresos que solo son instrumentalmente relevantes. Así, puede hablarse de dos tipos de pobreza que están íntimamente ligados, pues uno conlleva al otro: la pobreza de ingresos y la pobreza de capacidades (Sen, 2000; Nussbaum, 1997). Las capacidades determinan "las definiciones alternativas que una persona puede hacer o ser: los distintos funcionamientos que puede lograr" (Sen, 1996, p. 54). La relación entre capacidades y funcionamientos remite a "las cosas que las personas logran hacer o ser al vivir"; como el mismo autor señala, estas definiciones muestran una combinación de "quehaceres y seres", donde el concepto de calidad de vida adquiere relevancia "en términos de la capacidad para lograr funcionamientos valiosos". Este enfoque de pobreza recupera los aspectos culturales, simbólicos y la experiencia. Las reflexiones teóricas muestran la complejidad del fenómeno de la pobreza, que obliga a analizar esa condición desde la experiencia de las personas "en situación de pobreza" (Pont Suárez, 2010).

Otra perspectiva alternativa en consonancia con Sen se encuentra entre los llamados teóricos de la exclusión, quienes llaman la atención hacia "cómo vive la gente"; postulan que los pobres presentan una variedad de problemas y privaciones que van más allá de los bajos ingresos y constituyen un círculo vicioso. De este modo, la pobreza es definida como un fenómeno multidimensional que debe incluir habilidades y capacidades del pobre para manejar su propia vida, capacidad de adaptarse, tener acceso a servicios, participar en la vida social o comunitaria de su grupo, tener seguridad, entre otros (Mitchell y Ashley, 2010).

La definición de pobreza que manejan los economistas no da cuenta de la variedad de problemas que afrontan día a día los ciudadanos. Tales estudios economicistas ofrecen una visión estática y unidimensional de las personas de bajos ingresos en un momento determinado del tiempo, incapaz de comprender aspectos multidimensionales, dinámicos y vinculados a la participación social implícitos en el concepto exclusión. En este contexto puede haber personas pobres sin estar absolutamente excluidas, como ocurre en el caso de colectivos cuyo nivel de vida se sitúa bajo un umbral de pobreza, pero que mantienen vínculos laborales y sociales para participar en sociedad; así como personas excluidas por motivos que abarcan prejuicios sociales, discriminación religiosa, sexual o racial y tener un ingreso por encima de tal línea de pobreza (Fundación Encuentro, 2001). 
Si se comparan los términos de pobreza y exclusión social se identifica que, aunque ambos pueden tener aspectos coincidentes y espacios de intersección, no por fuerza son sinónimos. En ese sentido, no conviene perder de vista el papel fundamental de los procesos de exclusión social, así como el hecho de que la pobreza es, casi siempre, la forma a través de la cual se manifiesta la exclusión. Pero los prejuicios y discriminaciones solo producen exclusión social, en última instancia, en la medida en que provocan incapacidad para lograr unos ingresos y un nivel de vida aceptables, generando una carencia de opciones y alternativas que quienes no son pobres, aunque estén excluidos en algún sentido, pueden, sin embargo, disfrutar (Tezanos, 2001, p. 60).

Entendemos por exclusión un proceso de acumulación de desventajas en una serie de ámbitos que vacían de contenido el concepto de ciudadanía: exclusión de un nivel de ingresos o de consumo mínimo, de empleo seguro y permanente, de una vivienda digna, de la educación, de las políticas de protección social, de la participación democrática, de los bienes públicos, de la vida social y familiar, etcétera.

Así pues, uno de los logros importantes del concepto de exclusión social es que obliga a centrar el debate en aspectos que la investigación convencional de la pobreza ha dejado al margen, como la trascendencia de las relaciones sociales, la multidimensionalidad del fenómeno o la necesidad de estudiar las dinámicas que conducen a la exclusión (Jiménez Ramírez, 2008). Por otro lado, el concepto de exclusión social permite recuperar la dimensión ideológica en torno a las relaciones de conflicto entre los diversos sectores y estratos sociales en términos de apropiación de los recursos y de los medios de producción y distribución de la riqueza.

En el caso del turismo rural comunitario se observa que, como mecanismo, falla en el combate contra la pobreza, ya que a ciertos individuos y grupos se les impide sistemáticamente el acceso a posiciones que les permitirían una subsistencia autónoma dentro de los niveles sociales determinados por las instituciones y valores en un contexto dado, es decir, empresas, agencias de cooperación y ong. La población campesina ve muy limitada su posibilidad de acceder a un trabajo remunerado más o menos estable. De hecho, un mecanismo de exclusión social se refleja en el proceso que califica y descalifica a una persona como trabajador en el contexto del capitalismo. El turismo representa un choque entre una actividad moderna y el mundo campesino, pues significa una experiencia ajena a las comunidades rurales indígenas o mestizas, esto es, se trata de una actividad ajena a la "vocación social del territorio". El campesino y su familia, por lo general, no han experimentado el ser turistas, ni mucho menos saben qué es un prestador de servicios turísticos; tampoco tienen conocimientos ni destrezas para imaginar, crear y gestionar una empresa de corte mercantil que compita en el mercado global. Al no tener idea de sus características, la gente no puede participar con pleno conocimiento en su diseño y gestión (Cañada, 2012) y, consecuentemente, en los beneficios. 


\section{Reflexiones finales}

La consideración del origen de la pobreza en un modo de acumulación de explotación y exclusión social lleva de manera inevitable a la necesidad de abordar el concepto de la pobreza (y su solución) desde un ámbito global y multidimensional, nunca meramente sectorial y mágico, en lugar de concebir el turismo como una posibilidad cuasi mágica de desarrollo económico al aumentar las oportunidades de trabajo asalariado, crear microempresas locales y generar ingresos comunitarios dentro de un mercado globalizado. Lo que debe destacarse es el aspecto relacional que las nociones de equidad/desigualdad o exclusión/ inclusión implican, además de sus múltiples dimensiones objetivas y subjetivas -emic y etic-. En este sentido, el turismo debe pensarse en cuanto fenómeno que ha derivado de una actividad que nace como un medio de producción bien definido en el sistema capitalista y que se ha adaptado por completo al sistema neoliberal. Cuando se habla del turismo como una herramienta para combatir la pobreza se le está concibiendo como una actividad económica capitalista en la que los beneficios hacia los más pobres solo llegarán cuando los beneficios sean abundantes para los grandes empresarios inversionistas.

El turismo pro pobre, en cualquiera de las modalidades que las empresas turísticas hayan definido para este "nicho de mercado" (turismo voluntario, turismo comunitario, turismo rural, etc.), sigue representando un mayor negocio para los actores externos a las comunidades, pues surge a partir de explotar la idea dominante de pobreza, centrada en la dimensión puramente económica y monetaria. Para generar un cambio positivo en los impactos sociales del turismo "pro pobre" se requiere problematizar las dimensiones que definan no solo las condiciones económicas (pobreza), sino también las relaciones sociales y políticas, por ejemplo las de igualdad-desigualdad y exclusión-inclusión.

Emplear pobres en las empresas turísticas; suministrar bienes y servicios a las empresas turísticas que empleen pobres; vender directamente bienes y servicios a los visitantes por los pobres (economía informal); crear empresas turísticas por los pobres -microempresas, pequeñas y medianas empresas, o empresas de base comunitaria (economía formal)-; poner impuestos sobre los ingresos o beneficios del turismo, cuya recaudación se destine a beneficiar a los pobres; fomentar las donaciones y el apoyo voluntario de las empresas turísticas y de los turistas; invertir en infraestructura, estimulada por el turismo, que beneficie también a los pobres de la localidad de forma directa o mediante el apoyo a otros sectores, etc. no cambia la situación estructural, por el contrario mantiene su inscripción dentro de la trayectoria histórica de las desigualdades sociales.

El proceso por el cual a ciertos individuos y grupos se les impide de manera sistemática el acceso a posiciones que les permitirían una subsistencia autónoma dentro de los niveles sociales determinados por las instituciones y valores en un contexto dado se agudiza con la introducción del turismo en la vida rural, la mayor parte de los casos así lo evidencian: trabajos precarios con altos índices de temporalidad y rotación del empleo, explotación en el trabajo y la pérdida del mismo, entre otros. 
Por lo anterior, lo que hace falta es recuperar y proponer nociones que contribuyan a superar estas limitaciones del concepto de pobreza tradicional, que no reproduzcan las condiciones actuales de desigualdad y exclusión, y permitan una intervención efectiva en el diseño de proyectos sociales, en general, y del turismo en particular.

Por parte de la academia y de las oNG se requiere un análisis más profundo y menos simplista del supuesto de que la pobreza se combate automáticamente con proyectos turísticos y, de este modo, no caer en engaños que llevan a la frustración y al desánimo a las comunidades que creen en ellos. De hecho, uno de los riesgos actuales del turismo rural comunitario es que después de la ejecución de numerosos proyectos de cooperación se consolide la idea de que es una actividad condenada al fracaso, sin revisar con minuciosidad las razones que lo habrían provocado. Por ello, en México, habría que revisar cuántos recursos han sido asignados a comunidades rurales para iniciar proyectos turísticos y cuántos han ayudado a sacarlas de "la pobreza".

\section{Fuentes consultadas}

Ashley, C. y Goodwin, H. (junio, 2007). “Turismo pro-pobre” ¿Qué ha ido bien y qué ha ido mal? Overseas Development Institute. Opinion, 80. Recuperado de http://www.odi. org.uk/sites/odi.org.uk/files/odi-assets/publications-opinion-files/142.pdf

Berger, P. y Luckman, T. (1972). La construcción social de la realidad. Buenos Aires: Amorrortu.

Boltvinik, J. (2001). Opciones metodológicas para medir la pobreza en México. Comercio Exterior, 51(10), 869-878.

Cañada, E. (2011). ¿Debe el turismo comunitario orientarse hacia el mercado de altos ingresos? Barcelona: Alba Sud.

Cañada, E. (2012). Turismo comunitario, un espacio en disputa. En J. Buades, E. Cañada y J. Gascón, El turismo en el inicio del milenio: una lectura crítica a tres voces (pp. 130-131). Madrid: Foro de Turismo Responsable.

Cañada, E. (2015). La comercialización del turismo comunitario en América Latina. Anuario de Estudios Centroamericanos, 41(1), 159-189.

Cañada, E. y Fandiño, J. M. (2009). Experiencias de turismo comunitario en Nicaragua. Aportes a la economía campesina. Managua: Edisa.

Cañada, E. y Gascón, J. (2007). Turismo y desarrollo: Herramientas para una mirada crítica. Managua: Enlace.

Ceirano, V. (2000). Las representaciones sociales de la pobreza. Cinta de Moebio, 9, 337350.

Collins, R. (1994). Cuatro tradiciones sociológicas. México: Universidad Autónoma Metropolitana-Iztapalapa.

Cuéllar, O. (1995). Perspectivas en el estudio de la pobreza. Entrevista con Julio Boltvinik, Fernando Cortés y Rosa María Rubalcava. Sociológica, 10(29), 181-208.

Estivill, J. (2003). Panorama de la lucha contra la exclusión social, conceptos y estrategias. Ginebra: Oficina Internacional del Trabajo. 
Forstner, K. (2004). Community ventures and access to markets: The role of intermediaries in marketing rural tourism products. Development Policy Review, 22(5), 497-514.

Fundación Encuentro. (2001). Informe España 2001. Una interpretación de su realidad social. Madrid: Autor.

Gascón, J. (2010). Limitaciones del turismo rural comunitario como instrumento de cooperación internacional. El concepto de Vocación Social del Territorio. En M. Nel-lo (ed.), Turismo, cooperación y desarrollo. Actas I Congreso coodtuR (pp. 81-82). Tarragona: Universidad Rovira y Virgili.

Gascón, J. (enero, 2011). La metodología "Pro-Poor Tourism": un análisis crítico. Opiniones en Desarrollo. Programa Turismo Responsable. Artículo 9. Recuperado de www.albasud.org info@albasud.org

Gascón, J. (2012). La metodología “Pro-poor Tourism” (PPT) un análisis crítico. En J. Buades, E. Cañada y J. Gascón, El turismo en el inicio del milenio: una lectura crítica a tres voces (pp. 157-171). Madrid: Foro de Turismo Responsable.

Gascón, J. (2013). The limitations of community-based tourism as an instrument of development cooperation: The value of the Social Vocation of the Territory concept. Journal of Sustainable Tourism, 21(5), 716-731.

Gergen, K. (2007). La psicología social como historia. En Á. Estrada y S. Diazgranados (comps.), Kennet Gergen, construccionismo social. Aportes para el debate y la práctica (pp. 3-26). Bogotá: Universidad de los Andes.

Goodwin, H. (2013). Turismo y reducción de la pobreza. En J. Gascón, S. Morales y J. Tresseras (eds.), Cooperación en turismo. Nuevos desafíos, nuevos debates (pp. 387-405). Barcelona: Foro de Turismo Responsable/Xarxa de Consum Solidari/coodtur/Universitat Oberta de Catalunya/Universitat de Barcelona.

Hernández, E. (2001). Retos para la medición de la pobreza en México. Comercio Exterior, $51(10), 860-868$.

Herrera, J. (junio, 2002). La pobreza en el Perú en 2001: Una visión departamental. Lima: Instituto Nacional de Estadística e Informática/Institut de Recherche pour le Développement. Recuperado de http:/ / repositorio.minedu.gob.pe/handle/123456789/244

Jiménez López, O. y Cavazos Arroyo, J. (2012). El turismo orientado a los pobres: una alternativa estratégica para los países en desarrollo. PASOS. Revista de Turismo y Patrimonio Cultural, 10(5), 451-465.

Jiménez Ramírez, M. (2008). Aproximación teórica de la exclusión social: complejidad e imprecisión del término. Consecuencias para el ámbito educativo. Estudios $\mathrm{Pe}$ dagógicos, 34(1), 173-186. Recuperado de https://dx.doi.org/10.4067/S071807052008000100010

Kadt, E. de (1979). Turismo: ¿Pasaporte al desarrollo? Madrid: Endymion.

Lewis, O. (1961). Antropología de la pobreza. México: Fondo de Cultura Económica.

Milano, C. (2016). Antropología, turismo y desarrollo en cuestión: el turismo comunitario a debate. Quaderns de l'Institut Català d'Antropologia, 32, 145-166.

Mitchell, J. y Ashley, C. (2010). Tourism and Poverty Reduction: Pathways to Prosperity. Londres: Earthscan.

Mitchell, J. y Muckosy, P. (mayo, 2008). A misguided quest: Community-based tourism in Latin America. Overseas Development Institute. Opinion, 102. 
Nussbaum, M. (1997). Capabilities and human rights. Fordham Law Review, 66(2), 273300. Recuperado de http://ir.lawnet.fordham.edu/flr/vol66/iss2/2

Ortiz Sandoval, L. (2004). Pobreza, ideología y construcción social. Población y Desarrollo, 26, 5-17.

Pérez, F. J., Barrera Pérez, O. D., Peláez, A. V. y Lorío, G. (2010). Turismo rural comunitario como alternativa de reducción de la pobreza rural en Centroamérica. Managua: Nitlapan-Universidad Centroamericana.

Picón Cruz, J. C. y Hernández Ulate, A. (s. f.). El turismo rural comunitario en los procesos de la nueva ruralidad: la experiencia latinoamericana. Recuperado de https:/ /www. aecit.org/files/congress/18/papers/42.docx

Pinto Faria, D. M. e Hidalgo Moratal, M. (septiembre, 2012). ¿Hay evidencias del turismo como un factor para aliviar la pobreza? Trabajo presentado en el $5^{\circ}$ Congreso Latinoamericano de Investigación Turística, São Paulo.

Pleumaron, A. (1994). The political economy of tourism. The Ecologist, 24(4), 142-148.

Pont Suárez, E. S. (2010). "Yo no me siento pobre". Percepciones y representaciones de la pobreza. Revista de Estudios de Género. La Ventana, 4(31), 37-63. Recuperado de http://www.scielo.org.mx/scielo.php?script=sci_arttext\&pi$\mathrm{d}=\mathrm{S}$ 1405-94362010000100004\&lng=es\&tlng=es.

Sen, A. K. (1996). Nueva economía del bienestar. Escritos seleccionados (Honoris Causa 11). Valencia: Universitat de València.

Sen, A. K. (2000). Social Exclusion: Concept, Application, and Scrutiny (Social Development Papers 1). Manila: Asian Development Bank.

Tezanos, J. F. (2001). La sociedad dividida. Estructuras de clases y desigualdades en las sociedades tecnológicas. Madrid: Biblioteca Nueva.

Unesco. (1976). The effects of tourism on socio-cultural values. Annals of Tourism Research, (4) 2, 74-105. 